\title{
Meeting Abstract
}

\section{Assessments for medical discharge in athlete patients undergoing anterior cruciate ligament reconstruction}

Evaluaciones para el alta médica en atletas sometidos a reconstrucción del ligamento cruzado anterior

\author{
San Martín $\mathrm{C}^{1}$, Berral FJ ${ }^{2}$, Torres $\mathrm{G}^{3}$ \\ ${ }^{1}$ Pht, MSc., School of Kinesiology, Pontificia Universidad Católica, Santiago Chile. Clínica MEDS, Santiago, Chile. \\ ${ }^{2}$ Doctor Medicine and Surgery. Laboratory of Biomechanics, Kinesiology and Cineanthropometry. University Pablo \\ Olavide. Seville. Spain. \\ ${ }^{3} \mathrm{Pht}$, School of Kinesiology, Pontificia Universidad Católica. Santiago. Chile.
}

The anterior cruciate ligament (ACL) injury and their respective treatment produce a very large economic and emotional cost for patients who suffer it. For this reason it becomes essential doing a good treatment that allows adequate return to sports with less risk of re injury for patients. To accomplish this goal, before patient discharge it is necessary to confirm that the knee is in optimal conditions to be subjected to great loads and range of motion during functional activities. For greater support in this decision, each day is becoming more important doing the following assessments to patients:

\section{a) Clinical assessment}

The recommendations are that the patient should have full range of motion, no pain or inflammatory signology posterior to sport activities and no functional sensation of instability during sports and activities of daily living.

Regardless of patient parameters on different test it is important to consider that it must meet at least 6 to 8 months after surgery for normal reintegration to their sports activities, since these are the periods in which the graft reaches adequate levels of maturation and withstands tensile strength levels similar to ACL in healthy subjects. If the patient wants to return to sports activities of a high risk level (in this injury), it is recommended that the patient completed two months of constant field sport exercises for reintegration prior to medical discharge in order to adapt progressively to sporting gestures and high physical demands that implies the practice of this sports.

\section{b) Ligament laxity test}

Special tests like Lachman's test can be performed, anterior drawer test or pivot shift, but it is recommended to objectify the anterior displacement of the tibia using the KT2000. Daniel y cols. 
have found that $92 \%$ of healthy normal subjects had a difference of anterior translation of the tibia between right and left side of $2 \mathrm{~mm}$ or less, therefore it is recommended that the post surgical outcome comes as close as possible to these numbers. Habitually values not exceeding 2,5 to $3 \mathrm{~mm}$ difference between the operated leg and the healthy one are used with the KT2000 (1).

c) Maximum muscular strength measurement

Regardless of age or activity carried out by the assessed, bilateral relations of quadriceps and hamstrings must be less than 10\% (2,3). In general, at lower isokinetic speeds, hamstrings produce $60 \%$ of torque values generated by the quadriceps (4).

Other studies suggest that the quadriceps hamstring ratio should be greater than $66 \%$ in men and greater than $75 \%$ in women (5).

d) Muscle strength measurement

To assess the resistance of the hamstring muscles (ACL synergist) it is suggested the use of the single leg bridge test to measure the resistance force mainly at the hamstrings and has been commonly used to predict hamstring tear (6).

The evaluation results are poor when less than 20 repetitions are performed, regular with 25 and good over 30 repetitions performed.

\section{e) Balance (SEBT)}

It has been seen a decrease in the scope of the Star Excursion Balance Test (SEBT) not only in the injured leg in patients with ACL injury but also on the healthy leg compared to a control group (7).

\section{f) Jump test}

The most commonly used tests are the single unilateral horizontal jumps, triple, cross bridge and time in 6 meters (8).

The vast majority of studies recommended that there should not be greater distance than 10 or $15 \%$ between the healthy and the injured limb. Along with this is very important to consider the quality of the jump and especially observe the amortization phase, since during this stage is where the vast majority of injuries occur (5).

g) Sensorimotor control assessment 
- The joint repositioning proprioceptive test, should not indicate differences greater than 3 degrees when repositioning the joint in a position previously described.

- Muscle activation delay test: when a disturbance is generated until the hamstring and quadriceps muscles contract, it should not spend more time than $120 \mathrm{~ms}$. If muscle activation exceeds this time the joint may be exposed to injury by increasing the time that passes without the protection that the muscles give.

- The pivot test after descending a step consist in a person going down a step and walking out to the same side of the leg that is being assessed in a direction of 90 degrees with respect to the initial position. What is being evaluated here is the internal rotation of the tibia relative to the femur, which should not exceed 18 degrees. If in the evaluation the established range is exceeded, the patient may have a rotational instability, which may be a risk factor for ACL injuries.

- The steadiness is assessed with a load cell where the patient is asked to perform a maximum voluntary contraction in sitting position with 90 degrees of knee flexion. $15 \%$ of the maximum force exerted is then obtained and a curve is drawn with a rise, a plateau and a decrease located on a screen in front of the patient. The patient being evaluated must follow the curve making a muscle contraction without leaving margins established in the figure.

h) Sporting gesture on the playing field assessment

It is very important to see the behavior of the athlete on the playing field, as this is the riskiest place for the player. Circuits of coordination, agility, E or W career can be made and then assess the various sporting gestures involving sport (8).

This observation should be performed in conjunction between technical and medical staff or by a health care professional that is an expert in sport.

i) Questionnaires

There are questionnaires with subjective methods such as Lysholm or KOOS (Knee Injury and Osteoarthritis Outcome Score) and others which mix the subjective opinion of patients with objective assessments as CKRS (Cincinnati Knee Ligament Rating System) and IKDC (International Knee Documentation Committee Knee Form) that are useful to see evolution or status of the patient's condition (9). 


\section{References}

1. Daniel DM, Malcom LL, Losse G. et al. Instrumented measurement of anterior laxity of the knee. J Bone Joint Surg Am. 1985; 67:720.

2. Rodríguez D, Seara N, Glavina B. Ratios isocinéticos de flexo-extensores de rodilla en jugadores de fútbol y rugby. Rev Iberoam Fisioter Kinesiol. 2006; 9(2):46-51.

3. Ayala F, Sainz de Baranda P, de Ste Croix M, Santoja F. Revisión de Validez y fiabilidad de los ratios de fuerza isocinética para la estimación de desequilibrios musculares. Apunts Med Esport. 2012; 47(176):131-42.

4. Hassani A, Patikas D, Bassa E, Hatzikotoulas K, Kellis E, Kotzamanidis C. Agonist and antagonist muscle activation during maximal and submaximal isokinetic fatigue tests of the knee extensors. Jour Elect Kines. 2006; 16(6):661-8.

5. Wilk K, Macrina L, Cain EL, Dugas J, Andrews J. Recent advances in the rehabilitation of anterior cruciate ligament injuries. J Orthop Sports Phys Ther. 2012; 42(3):153-71.

6. Freckleton G, Cook J, Pizarra T. The predictive validity of a single leg bridge test for hamstring injuries in Australian Rules Football Players. Br J Sports Med; 2014; 48(8):71320.

7. Herrington L, Hatcher J, Hatcher A, McNicholas M. A comparison of Star Excursion Balance Test reach distances between ACL deficient patients and asymptomatic controls. The Knee. 2009; 16:149-52.

8. Myer GD, Paterno MV, Ford KR, Quatman CE, Hewett TE. Rehabilitation After Anterior Cruciate Ligament Reconstruction: Criteria-Based Progression Through the Return-to-Sport Phase. J Orthop Sports Phys Ther. 2006; 36(6):385-402.

9. Arcuri F, Abalo E, Barclay F. Uso de escores para evaluación de resultados en cirugía del ligamento cruzado anterior. Artroscopia. 2010; 17(3):241-7.

\section{Correspondencia:}

Cristóbal Fernando San Martín Mohr

Carlos XII 173, Depto 1102, Las Condes, Santiago, Chile.

$+56993992149$

cristobalsanmartin@hotmail.com

Recibido: 22-06-2016 Aceptado: 